DOI 10.37882/2223-2982.2020.11.11

\title{
ВЛИЯНИЕ СОТРУДНИЧЕСТВА СЕМЬИ И ШКОЛЫ НА ФОРМИРОВАНИЕ ПЕДАГОГИЧЕСКИХ КОМПЕТЕНЦИЙ У РОДИТЕЛЕЙ
}

\section{THE INFLUENCE OF FAMILY AND SCHOOL COOPERATION ON THE FORMATION OF PEDAGOGICAL COMPETENCES IN PARENTS}

\section{S. Guliyeva}

Summary: Today, reforms are being implemented in the field of education in our country. A new infrastructure related to education is being created, the content is being updated, and teaching staff is being trained. These are not enough to succeed in education. Because the views of the vast majority of parents on the education of children do not meet modern requirements. Family-school ties weaken year after year as students move into the upper grades. Parents' pedagogical skills lag behind the requirements of educational reform. The article examines the impact of family-school cooperation on the formation of pedagogical competencies in parents, analyzes various models of development of pedagogical skills in parents, traditional and non-traditional forms of parent-teacher cooperation.

Keywords: pedagogical competence, cooperation, school, competent parents, education.

\author{
Гулиева С. М. \\ Бакинский славянский университет \\ gmor68@inbox.ru
}

Аннотация: Сегодня в нашей республике в сфере образования реализуются реформы, создается новая инфраструктура, связанная с образованием, обновляется содержание, идет подготовка педагогических кадров. Этого недостаточно, чтобы добиться успеха в образовании. Потому что взгляды подавляющего большинства родителей на воспитание детей не соответствуют современным требованиям. Связи между семьей и школой ослабевают из года в год по мере того, как ученики переходят в старшие классы. Педагогические навыки родителей отстают от требований образовательной реформы. В статье исследуется влияние сотрудничества семьи и школы на формирование педагогических компетенций у родителей, анализируются различные модели развития педагогических навыков у родителей, традиционные и нетрадиционные формы взаимодействия родитель-педагог.

Ключевые слова: педагогическая компетентность, сотрудничество, школа, компетентные родители, образование.
B Азербайджанской Республике семья находится под полной защитой государства. Права и обязанности каждого члена семьи охраняются законом. В целях обеспечения физического и интеллектуального развития подрастающего поколения с раннего возраста, получения полного среднего образования, нравственной и духовной зрелости государством наряду с образовательными учреждениями определены права и обязанности родителей. Каждый родитель должен воспитывать своих детей в духе гуманизма, патриотизма, трудолюбия, преданности идеологии азербайджанства, уважения к истории, литературе, языку, национально-духовным и общечеловеческим ценностям. В Семейном Кодексе Азербайджанской Республики сказано, что «родители обязаны обеспечивать основное общее образование детей и воспитывать их» [1].

Родители должны работать с образовательными учреждениями своих детей, чтобы справиться с этой обязанностью. Особого внимания заслуживают два аспекта сотрудничества родителей и учителей:

1. родители регулярно получают информацию об интересе своих детей к обучению, навыках общения с одноклассниками и учителями, поведении, посещаемости, учебных достижениях, профессиональном интересе, знакомятся с эффективной и качественной организацией учебного процесса на уроках;

2. родители участвуют на организованных школой мероприятиях, семинарах, презентациях проектов, посвященных воспитанию детей, родительским собраниям, руководству школы, повышая их педагогическую культуру. Эффективная организация взаимодействия родителей и учителей (индивидуального или коллективного) играет важную роль в формировании педагогических компетенций у родителей. Сотрудничество родителей каждого ученика с учителем важно для определения правильного образа жизни этого ученика. В.А. Сухомлинский сравнивал учителя с врачом и писал: «Как врач исследует множество факторов, от которых зависит здоровье человека, так и педагог должен исследовать духовный мир ребенка» $[2$, c.45]. Если у родителей нет исчерпывающей 
научной информации об ученике, учителю будет сложно диагностировать и прогнозировать развитие детей. Это требует от родителей и учителей комплексного подхода к одному и тому же вопросу. Для этого родитель, который приходит в школу с ребенком, должен с первого дня стать участником педагогического процесса.

Теоретическая разработка и практическое применение форм и способов взаимодействия учителя и родителей всегда были в умах азербайджанских педагогов. Изучение взаимоотношений педагогов и родителей в воспитании подрастающего поколения началось преимущественно во второй половине XIX века. Создание государственных школ в Азербайджане, распространение просветительского движения, наряду с обучением детей школьного возраста, заставили их родителей учиться в пятничных и вечерних школах, учрежденных благотворительными организациями. Если в то время российские педагоги К. Душинский, В.П. Вахтеров, П.Ф. Каптерев, П.Ф. Лесгафт писали о необходимости согласования семейного и школьного образования, то роль родителей (особенно матери) в воспитании детей была подчеркнута на социально-педагогических воззрениях азербайджанских педагогов М.Ф. Ахундова, А.А. Бакиханова, М.Ш. Вазеха, Г.Б. Зардаби.

М.Ф. Ахундов констатировал, что «держать женщин в неволе и в чадре - большой вред» [3, с.112], «Не оставляйте их без образования» [3, с.112]. Г. Б. Зардаби заявил, что дети должны получить первое воспитание в семье, от матерей, и написал, что если матери не помогают, школа не может воспитывать ребенка одна [4, с.201]. Маммадага Шахтахтинский говорил, что мать оказывает большое влияние на воспитание ребенка, и многое передается от матери к ребенку: «Матери - естественные воспитатели детей» [5, с.139]. Ф.Б. Кочарли, Р. Эфендиев, Н. Нариманов, Дж. Мамедгулузаде, У. Гаджибеков, А. Гусейнзаде, С.М. Ганизаде, Ф. Агазаде, А. Саххат и другие ценили роль матери в воспитании детей, боролись за образование женщин и за то, чтобы они стали активными членами общества. М.А. Расулзаде подчеркивал их важную роль в духовной жизни нации, считая матерей носителями национального мышления. Н. Нариманов считал развитие природных способностей детей важным условием семейного и школьного воспитания.

В целом конец XIX - начало XX века - очень важный этап в образовательно-воспитательной культуре Азербайджана. В этот период азербайджанские мыслители серьезно занялись как теоретико-методологическими, так и практическими проблемами воспитания, сделали серьезные научные обобщения о нравственном, духовном, физическом и духовном развитии подрастающего поколения. Их богатое педагогическое наследие вклю- чает ценные сведения о семейном воспитании, образовании и воспитании женщин, а также о сотрудничестве родителей и учителей. В результате анализа теоретического наследия классиков педагогической мысли можно выделить следующие модели сотрудничества семьи и школы в тот период:

1. модель «школа - центр обучения в социальной среде». Здесь вокруг ребенка были объединены все средства обучения и воспитания.

2. традиционная школьная модель, которая влияет на улучшение образовательной среды в семье, расширение родительско-педагогических отношений.

3. модель «горизонтальных линий». Эта модель была широко распространена в Азербайджане в 1920е годы. В этой модели учитель должен был играть важную роль в педагогике среды во вновь создаваемых образовательных учреждениях, в организации саморазвития, самоорганизации и самообразования детей и родителей.

Во второй половине 1930-х годов демократические подходы к сотрудничеству учителей и родителей отошли на второй план, а авторитарное влияние школы на семью усилилось. В этот период применялась модель «школы социального контроля». Учитель, отвечающий за поведение детей в школе, на улице и в семье, также имел право судить детей. Все это означало жесткий контроль над семейным воспитанием, детско-родительскими отношениями в семье, поведением детей в семье. Каждый ребенок дошкольного возраста был предварительно зарегистрирован в школьном реестре по месту жительства. Как правило, школа не учитывала мнения и пожелания родителей или учеников. Школа доводила до родителей свои образовательные потребности через «родительские университеты», «педагогические лекции» и индивидуальные беседы. Поскольку программы педагогической подготовки родителей разрабатывались школой, содержание, формы (коллективные, индивидуальные) и методы (лекции, индивидуальные беседы) проводимой для них педагогической работы определялись учителями.

Юридически семья находилась в зависимости от школы и не могла проявлять инициативу. Школа оказала значительное влияние на семью из-за отсутствия механизма мониторинга и формальной оценки проводимой воспитательной работы. От семьи требовалось безоговорочно поддерживать политику государства и школы в области образования, следить за обучением и поведением своих детей, повышать их политическую и педагогическую подготовку на родительских собраниях и «педагогических лекциях», а также содействовать школьной экономической и образовательной деятельности. 
В 1950-е годы предпочтение было отдано более демократичной модели сотрудничества учителей и родителей. Смягчение общественно-политической жизни в послевоенный период также серьезно отразилось на семейных и школьных отношениях. А. Сеидов, М. Мехдизаде, М. Мурадханов, Б.Б. Комаровский, И. Валиханлы и другие отметили важность установления взаимоотношений между семьей и школой на основе демократических подходов в формировании школьной личности. Выделены два основных направления содержания работы учителя с родителями: 1) воспитание характера в детях; 2) контроль за дисциплиной и успеваемостью детей [6].

После смягчения в обществе произошло изменение содержания дисциплинарного воспитания детей в семье и школе. Давление школы на семью сменилось равноправным сотрудничеством. Воспитывались педагогические и психологические требования в воспитании детей как в школе, так и в семье. Вместо того, чтобы привлекать школьников к обучению административными средствами, была выдвинута идея создать среду, в которой они смогут повысить свою инициативу, творческий потенциал и дисциплинированность.

В 60-70-е годы XX века процесс демократизации продолжился во взаимодействии семьи и школы. В первую очередь это было связано с концепцией формирования нового человека - разносторонней и гармонично развитой личности. Воспитание подрастающего поколения, отличающегося нравственной чистотой и физическим совершенством, может стать возможным благодаря взаимодействию семьи и школы. В то время акцент делался на формировании гражданского отношения школьников к жизни и общественной деятельности. Усовершенствованы формы и способы взаимоотношений между семьей и школой. Повышение уровня образования родителей придало новое содержание и направление сотрудничеству родителей и учителей.

Во второй половине 1980-х и в 1990-х гг. в системе образования начались изменения в результате реформ в обществе. В связи с этим ведутся интенсивные исследования, направленные на решение вопроса взаимодействия учителей и родителей. В этот период в теории и на практике совершенствуются формы и методы взаимодействия учителей и родителей, определяется содержание работы школы с семьей, выдвигается идея дифференцированного подхода к развитию педагогической культуры у родителей. Уточнены теоретические положения педагогического просвещения родительских групп, исследованы причины семейных конфликтов, даны конкретные рекомендации родителям по воспитанию детей.

Социально-экономические изменения в обществе в последние десятилетия привели к значительным изменениям в сотрудничестве родителей и учителей. Были созданы современные учебные заведения (гимназии, лицеи), начали работать школы английского, французского, немецкого и турецкого языков. Существенные изменения претерпели не только содержание образования, но и формы обучения. У родителей была возможность изучить услуги разных учебных заведений, чтобы выбрать то, что им больше нравится. В результате появилась возможность прямо и косвенно влиять на школу.

В 1930-х и 1940-х годах у школы была прекрасная возможность влиять на семью, но в 1950-х годах это влияние стало постепенно снижаться. В 60-х и 70-х годах отношения между школой и семьей превратились в партнерство равных субъектов. За последнее десятилетие возможности родителей влиять на школу значительно расширились. Наряду со всем этим в поведении детей есть много недостатков. Социальные сети, телевидение, Интернет и другие источники информации негативно влияют на воспитание детей на основе национально-духовных ценностей.

Одним из факторов, негативно влияющих на сотрудничество семьи и школы, является резкая разница социально-экономических показателей семьи. В результате социального расслоения населения у каждой родительской группы возникли разные образовательные потребности. В соответствии с целями того социального класса, который они представляют, родители определили адекватные требования и ожидания в отношении образования и развития своих детей. Близкий уровень образования родителей определенных социальных групп к учителям создал иную модель сотрудничества семьи и школы. В результате социального расслоения, пронизывающего образовательный процесс и воспитание подрастающего поколения, школа стала объектом серьезной критики со стороны родителей, СМИ и общества в целом.

Проблема вовлечения родителей в педагогический процесс в очередной раз стала предметом научных дискуссий исследователей, и были определены единые педагогические требования к родителям (ответственность за будущее детей, физическое, умственное, нравственное воспитание). Исследователи, изучающие теоретические и технологические вопросы семейного воспитания, представили понятия педагогического сотрудничества, «эффективное образовательное сотрудничество» и определили виды сотрудничества (приглашение родителей в школу, родительские собрания, «День родителей», родительские университеты, педагогические лекции и т. д.). Эффективная организация педагогического сотрудничества изучалась как важное условие повышения эффективности воспитательной деятельности семьи. 
Современная модель сотрудничества семьи и школы привлекает внимание своей демократичностью, гуманизмом и современностью. Теоретические основы современной модели отражены в «Законе Азербайджанской Республики об образовании» [7].

Сотрудничество учителей и родителей важно на всех этапах школьной жизни, но особенно важно в первые годы обучения ребенка. В эти годы ребенок еще не может контролировать свои чувства и поведение, потому что он очень близок к семье. В раннем школьном возрасте у ребенка меняется вид деятельности, учеба становится ведущей деятельностью, и в общении и отношениях с другими людьми возникает иная ситуация. Образ жизни ребенка также меняется по мере появления новых обязанностей (образование, школьная дисциплина и т. д.). Сотрудничество родителей и учителей особенно важно на этом этапе, так как формирование личности учеников начальных классов происходит в семье и в школе (в процессе общения с одноклассниками и учителями) под влиянием новых занятий и людей, с которыми они общаются. Адаптация первоклассников к школе тесно связана с их психологической подготовкой в семье. Большинство родителей оценивают готовность своего ребенка к школе по уровню знаний. По их словам, если дети умеют считать, читать стихи, узнавать буквы, то они готовы к школе. Это неправильный подход. Прежде чем учить детей чтению и письму, родители должны привить им чувство уверенности в себе, научить их просто выражать свои мысли и побудить их пойти в школу. Родители должны серьезно отнестись к социализации своих детей, с этой целью отвести их в детский сад и проводить с ними время. Поскольку педагогическая деятельность является функцией учителя, он систематически и последовательно преподает ученикам необходимые знания в соответствии с их возрастом и уровнем познания. Поскольку дети в семье психологически не готовы к школе, они не могут адаптироваться к учителю и одноклассникам как в дошкольной группе, так и в школе, и выражают свои протесты в слезах. Основная причина этого - неспособность родителей создать среду для общения своих детей в семье. У таких детей возникают недопонимания со сверстниками и учителями из-за агрессии и раздражительности. Начальная школа - это особый этап в жизни ребенка. На этом уровне образования ученики требуют особого внимания как со стороны учителей, так и со стороны родителей. После поступления ребенка в школу происходит переход к учебной деятельности, расширяется взаимодействие с окружающим миром, затем у него начинает формироваться положительное отношение к образованию, школе, учителям и сверстникам и новая социальная позиция. Решение новых задач и понимание новых обязанностей зависят от эффективной организации сотрудничества учителей начальных классов и родителей. Есть разные формы и компоненты взаимодействия. Организационно-процедурная составляющая взаимодействия учителя и родителей включает в себя систематическое и постоянное взаимодействие учителей и родителей, организацию и выполнение работ, связанных с воспитанием ребенка, а также методы, инструменты, формы и принципы взаимодействия учителей и родителей.

Эффективность сотрудничества учителя и родителей зависит от правильного выбора и применения методов. «В педагогическом смысле метод - это система действий, осуществляемых с целью оптимального донесения до учащихся реалий жизни, вооружения их знаниями, умениями, привычками в рамках программы, формированием у учащихся необходимых качеств (патриотизм, трудолюбие, смелость, доброта и др.)» [8, с.67] . В этом процессе под руководством учителя студенты приобретают систему знаний, умений и навыков. Методы, являющиеся индикатором эффективности взаимодействия учителя и родителей, - это способы взаимодействия учителей, учеников и их родителей, которые являются участниками всего педагогического процесса для решения образовательных задач. Чтобы предсказать результат сотрудничества семьи и школы в воспитании детей, педагог должен знать особенности методов педагогической деятельности. Как упоминалось выше, успешный результат зависит от выбора и применения наиболее оптимальных методов.

Правильный выбор методов взаимодействия педагога с родителями играет важную роль в педагогическом просвещении родителей, формировании педагогической культуры. Родитель с необходимыми педагогическими навыками отличается своей репутацией и личным примером применения правильного метода в воспитании своих детей. Учитывает определенные требования при организации процесса воспитания в семье.

В наше время в сотрудничестве учителя и родителей чаще всего используются следующие методы: лекции, интервью, консультации, дискуссии, дебаты и тренинги. Совместимость выбранного метода с формой взаимодействия учителя и родителей (коллективное, групповое, индивидуальное) обеспечивает его эффективность.

На формирование личности ребенка в семье влияет множество факторов: 1) личностный потенциал и характер ребенка; 2) участие обоих родителей в воспитании детей; 3) ожидание единства образовательных воздействий (между членами семьи, между семьей и школой); 3) планомерная, последовательная и непрерывная воспитательная работа в семье; 4) уважение к личности ребенка; 5) искренность и доброта родителей к созданию здоровой среды для воспитания ребенка. 
В сотрудничестве учителя и семьи используются формы массовой работы. На практике также распространены индивидуальные консультации и домашние визиты в сотрудничестве между учителем и родителями. Традиция, когда учителя отправляются домой с целью изучения педагогического потенциала родителей и оказания педагогической поддержки семье, восходит к 70-80-м годам. Они собрали обширную информацию об индивидуальных характеристиках детей. Учителя имели полное представление об успеваемости учеников и уровне образования. К сожалению, в последнее время эта традиция была забыта.

До последнего времени учителя использовали в практической работе с родителями учеников в основном традиционные формы семейно-школьных отношений. В наше время наряду с традиционными формами работы выполняются также нетрадиционные формы работы. В то время, когда в 2020 году миру угрожает пандемия коронавируса, все учебные заведения Азербайджана временно приостановили свою деятельность в рамках превентивных мер. Для обеспечения непрерывности обучения занятия были организованы на платформах Zoom, Microsoft Teams, Skype. Эффективное использование этих платформ принесло новый контент в сотрудничество учителей и родителей. Возникли нетрадиционные формы сотрудничества между учителем и родителями, т.е. новая модель (онлайн-консультации, онлайн-обсуждения, онлайн-встречи в классе и т. д.). Фактически, этот процесс начался в некоторых школах страны. Некоторые государственные и частные школы уже много лет внедряют электронное правительство, электронные журналы и электронные дневники. С помощью современных технологий родители знакомились с организацией учебного процесса в школе, где их дети учатся дома или на работе в режиме онлайн, отслеживали результаты обучения своих детей, общались с учителями и обменивались мнениями. Был положительный опыт в области виртуальной школы. Эпидемия коронавируса ускорилась и расширила охват. Zoom, Microsoft Teams, Skype имеют возможность работать на платформах. Родители студентов, обучающихся онлайн, также должны были изучить программу, чтобы поддерживать связь с учителями и помогать своим детям. Хотя введение дистанционного образования в средних школах кажется многообещающим, нет сомнений в том, что онлайн-встречи учителей и родителей будут продолжаться.

Эффективность результатов сотрудничества учителя и родителей зависит не только от применения оптимальных методов, но и от учета определенных принципов. Обобщая научно-педагогическую литературу и имеющийся опыт, принципы взаимодействия педагогов и родителей можно определить следующим образом:
1) принцип единства воспитательных воздействий; 2) принцип оптимизма; 3) индивидуальный подход; 4) субъективность; 5) гуманизация межличностных отношений.

Как и в процессе обучения, применение этих принципов в сотрудничестве учителя и родителя должно быть комплексным и действовать в форме органического единства. Учитывая, что эти принципы создают концепцию сотрудничества между учителем и родителями, мы можем представить его как систему. Тогда каждый из этих принципов действует как компонент этой системы. Для эффективного применения этих принципов должны быть соответствующие педагогические условия, основанные на сотрудничестве учителей и родителей в начальной школе.

Под педагогическими условиями понимается совокупность содержания, формы, методов и средств, направленных на решение поставленных образовательных задач. Учителя начальной школы должны работать с родителями, чтобы комплексно применять вышеуказанные принципы, принимая во внимание внешние (средовые) и внутренние факторы (педагогические потребности родителей и т.д.), субъективные и объективные влияния на процесс. По этой причине при установлении контакта с семьей учителя должны обращать особое внимание на два аспекта: 1) организационный; 2) психолого-педагогический.

Учет как организационных, так и психолого-педагогических аспектов требует педагогической компетентности и профессионализма от учителей начальных классов. Решение поставленных задач в сотрудничестве педагога с родителями зависит, с одной стороны, от выбора подходящих условий сотрудничества, знакомства родителей с семьей, правильного планирования организационной работы, а с другой стороны, от учета педагогических и психологических факторов.

На наш взгляд, хотя условий для эффективности взаимодействия учителя и родителей много, учитель должен обратить особое внимание на 4 условия:

1. Понимание учителем необходимости взаимодействия с родителями как цели и критерия учебного процесса. Цель - главное условие учебного процесса, прогнозирование результатов деятельности. Цель также должна быть диагностической.

2. В процессе сотрудничества подходить к родителям индивидуально, проявлять творческий подход, отдавать приоритет диалогу на встречах. Это условие отражает индивидуальный подход учителя. Педагог разрабатывает стратегию учебной деятельности и определяет тактику действий в конкретной ситуации.

3. Педагог имеет профессиональные коммуникатив- 
ные навыки. По мнению психологов, коммуникативные навыки являются неотъемлемой частью культуры общения. Во время взаимодействия с родителями педагог должен выполнять все функции общения (контакт, информацию, мотивацию, координацию, понимание, создание эмоционального состояния у участников, влияние и др.), быть организатором коллективной деятельности и взаимоотношений. Это требует от учителя ряда коммуникативных навыков.

4. Способность учителя сочувствовать и размышлять. Это состояние тесно связано с третьим условием. Тот факт, что учитель сочувствует к родителям или ученикам, что он взволнован неудачей ученика, разделяет его чувства и эмоции, является признаком его сочувствия. Учитель также проявляет сочувствие к тому, чтобы чувствовать эмоциональное состояние ученика через его или ее поведение, действия и выражения лица в процессе обучения.

Поскольку образовательный процесс связан с социально-экономическими и культурными потребностями общества, модели сотрудничества учителя и родителей изменились в соответствии с этой потребностью за последние сто лет. Формируются новые модели взаимодействия учителя и родителей в соответствии с требованиями современности. При создании новой модели взаимоотношений школы с родителями младших школьников может оказаться эффективным учет потребностей общества, цели школы, а также педагогического потенциала и индивидуальных особенностей семьи.

\footnotetext{
1. Azərbaycan Respublikasının ailə məcəlləsi. http://www.e-qanun.az/code/10

2. Сухомлинский В.А. 0 воспитании: Золотой фонд педагогики / сост.Д.И. Латышева. М.: Школьная пресса, 2003. - 192с.

3. Axundov M.F. Әsərləri. 3 cilddə. II c., Bakı: Elm, 1988, 388 s.

4. "Okinçi" qəzeti (1875-1877). Tam mətni. (ərəb əlifbasından kirill əlifbasına çevirəni və nəşrə hazırlayanı: T.Həsənzadə). Bakı: Azərnəşr, 1979, 464 s.

5. Şahtaxtlı M. Seçilmiş əsərləri. Bakı: Çaşığlu, 2006, $432 \mathrm{~s}$.

6. Muradxanov M., İtelson L. Məktəbdə şüurlu intizam tərbiyəsi. Bakı: Azərnəşr, 1955, 120 s.

7. Azərbaycan Respublikasının təhsil Qanunu. “Xalq qəzeti" 19 iyun 2009-cu il

8. Zhmədov B. Azərbaycan dili təliminin qanunları, prinsipləri və metodları. Bakı: Maarif, 1974, $114 \mathrm{~s}$.

9. Paşayev Ә., Rüstəmov F. Pedaqogika, Bakı: Elm və təhsil, 2012, $463 \mathrm{~s}$.

10. Abbasov A. Ailə pedaqogikası. Bakı: Mütərcim, 2019, $270 \mathrm{~s}$.

11. Çələbiyev N. Ailə psixologiyası. Bakı: Mütərcim, 2015, $422 \mathrm{~s}$.
}

○ Гулиева С.М. (gmor68@inbox.ru) 